03.1;03.4;05.1

\title{
Одиночное и совместное движение суперкавитирующих ударников в сверхзвуковом режиме в воде
}

\author{
(ㄱ А.Н. Ищенко, В.В. Буркин, А.С. Дьячковский, И.В. Майстренко, К.С. Рогаев, А.Ю. Саммель, А.В. Чупашев \\ Научно-исследовательский институт прикладной математики и механики Национального исследовательского Томского \\ государственного университета, Томск, Россия \\ `E-mail: chupashevav@gmail.com
}

Поступило в Редакцию 27 июля 2020г.

В окончательной редакции 14 августа 2020 г.

Принято к публикации 16 августа 2020г.

Рассматриваются особенности движения в воде одного и двух суперкавитирующих ударников при их одновременном входе в воду со скоростями, превышающими скорость звука в среде. Разработаны условия, обеспечивающие неразрушающий вход ударников в воду и устойчивое движение по прицельной траектории в трансзвуковом диапазоне скоростей. Получено устойчивое совместное движение в воде двух ударников на сверхзвуковой скорости.

Ключевые слова: групповое движение в воде, суперкавитация, ударник, кавитатор, сверхзвуковая скорость, гидробаллистическая трасса.

DOI: 10.21883/PJTF.2020.23.50343.18484

Движение в воде при высоких скоростях, в том числе превышающих скорость звука [1], наиболее эффективно в режиме суперкавитации, когда торцевая поверхность движущегося тела - кавитатор - образует в воде каверну (газопаровую полость), полностью охватывающую тело [2-4]. Настоящая работа является продолжением исследований [5], в которых реализовано совместное движение в воде двух ударников при скоростях около $1100 \mathrm{~m} / \mathrm{s}$. Цель работы заключается в разработке условий метания и конструкций, обеспечивающих неразрушающий вход и устойчивое движение в воде в сверхзвуковом диапазоне скоростей одного и двух ударников при пушечном старте в единой сборке.

Метание производилось в условиях гидробаллистической трассы [6]. В процессе движения ударников по траектории измерялась их скорость в трех сечениях: на выходе из ствола ускорителя, через $0.7 \mathrm{~m}$ пути от входа в воду и через $2.3 \mathrm{~m}$. Через $2.6 \mathrm{~m}$ на траектории была установлена стальная мишень. Трасса наполнялась пресной водой с температурой $15^{\circ} \mathrm{C}$, в таких условиях скорость звука, согласно формуле Лероя [7], составляет около $1464 \mathrm{~m} / \mathrm{s}$.

Ударники в составе разделяемой метаемой сборки разгонялись в канале гладкоствольной баллистической установки калибром $30 \mathrm{~mm}$. На рис. 1 представлены рассматриваемые конфигурации двух вариантов подкалиберного ударника из сплава ВНЖ. Ударник формы I, показанный в верхней части рисунка, выполнен в виде усеченного конуса, ударник формы II, показанный в нижней части, состоит из двух конусов, упрочняющих его конструкцию.

На рис. 2 приведены экспериментальные и расчетные зависимости скорости от пройденного в воде пути для обеих форм ударников. Расчет проводился путем интегрирования уравнения движения материальной точки постоянной массы. Сила сопротивления $F$ находилась по формуле $F=C_{x} \rho S_{c} V^{2} / 2$, где $S_{c}$ - площадь кавитатора ударника, $V-$ скорость ударника, $\rho-$ плотность воды, $C_{x}=0.82(1+\sigma)-$ коэффициент сопротивления, $\sigma-$ число кавитации.

Рассматривается серия из шести опытов, в которой производилось метание ударников при трансзвуковых скоростях. В опытах № 1-3 проводилось метание ударников формы I (рис. 2,a), в опытах № 4-6 ударников формы II (рис. 2, $b$ ). Символами на рисунке показаны измеренные в эксперименте скорости, линиями - соответствующие номеру эксперимента расчетные зависимости падения скорости согласно формулам из работ $[2,5]$.

В опыте № 1 (рис. 2,a) скорость ударника в момент входа в воду составила $1312 \mathrm{~m} / \mathrm{s}$, после чего он успешно преодолел путь до мишени по прицельной прямолинейной траектории. Различие величин рассчитанных и измеренных в экспериментах скоростей движения в воде составило менее $1 \%$.

При анализе результатов опытов № 2, 3 с увеличенной до сверхзвуковой скоростью входа в воду было отмечено, что ударник формы I в расчетах имеет в среднем на 2-3\% бо́льшую скорость, чем полученная в эксперименте. В опыте № 2 при начальной скорости $1523 \mathrm{~m} / \mathrm{s}$ ударник формы I разрушился после преодоления в воде пути 1.5-2 m, а его фрагменты полностью

II

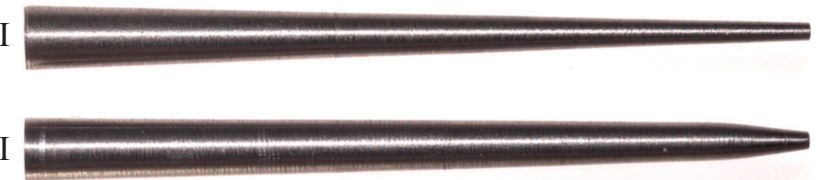

Рис. 1. Фотография применяемых подкалиберных ударников. 

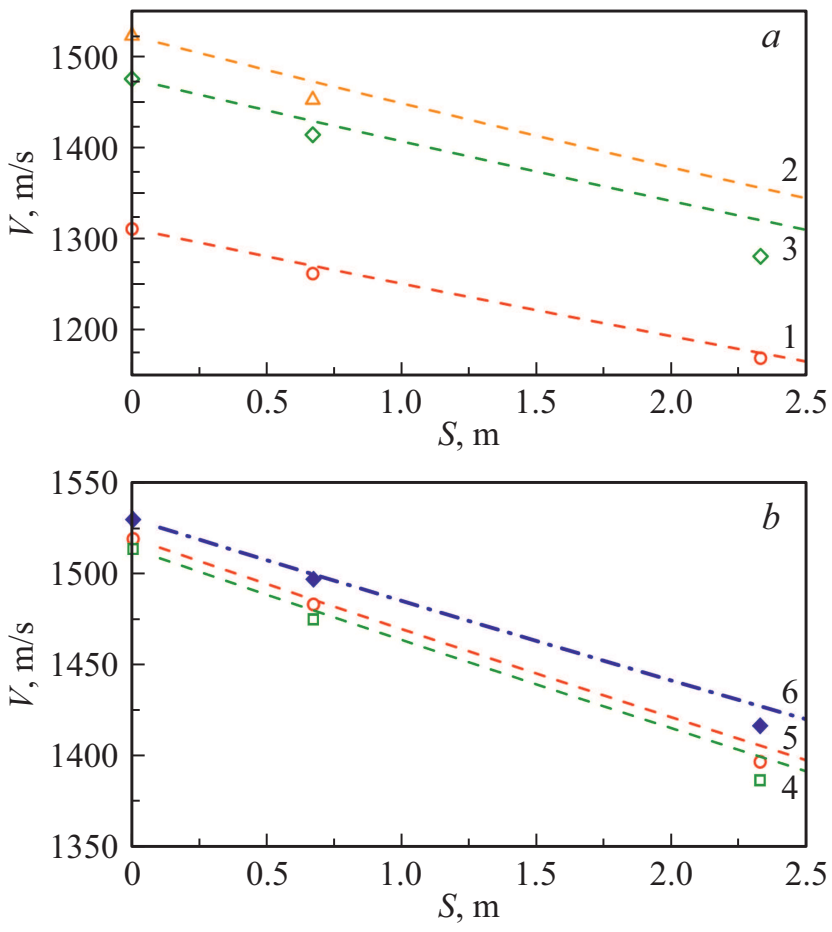

Рис. 2. Зависимости скорости ударников от пройденного в воде пути. $a$ - для ударника формы I; $b-$ для ударника формы II. Символами показаны экспериментальные данные, линиями - соответствующий каждому эксперименту расчет. Цифры 1-6 - номера опытов.

затормозились в результате трения о воду. Измерение площади поверхности кавитатора под микроскопом выявило ее увеличение на $12 \%$ по сравнению с пер- воначальной, что может быть следствием начавшегося процесса пластической деформации материала ударника при движении в воде. Увеличение площади кавитатора способствует росту силы лобового сопротивления, вследствие чего будет наблюдаться отличие скорости ударника в эксперименте от расчета, в котором площадь кавитатора считается постоянной. Разрушение ударника указывает на то, что конструкция ударника формы I не обеспечивает достаточной прочности его корпуса при движении в воде со скоростями, близкими к скорости звука.

Для повышения прочности носовой части ударника в его профиль был добавлен еще однин конус, позволяющий укрепить общую конструкцию ударника (рис. 1) с сохранением диаметра кавитатора. В опытах № 4 и 5 (рис. 2,b) было произведено метание одиночного усиленного ударника формы II в воду со скоростями 1512 и $1518 \mathrm{~m} / \mathrm{s}$ соответственно, различие измеренных в эксперименте скоростей ударников в этих опытах не превысило 1\%. Наблюдается устойчивое движение ударников по прямолинейной прицельной траектории до мишени.

Для ускорения в метаемой сборке, представленной на рис. 3, $a$, использовались два ударника формы II. Ударники в сборке помещались параллельно и устанавливались в стволе друг над другом. Перед входом в воду расстояние между кавитаторами ударников в наблюдаемой плоскости составило $16 \mathrm{~mm}$. На рис. $3, b$ приведена фотография из опыта № 6 (рис. 2, $b$ ), в котором два ударника вошли в воду со скоростью $1529 \mathrm{~m} / \mathrm{s}$. Расчетные и экспериментальные значения скоростей одинаковых ударников очень близки, поэтому на рис. $2, b$ в опыте № 6 показан только нижний ударник. Ударники в момент
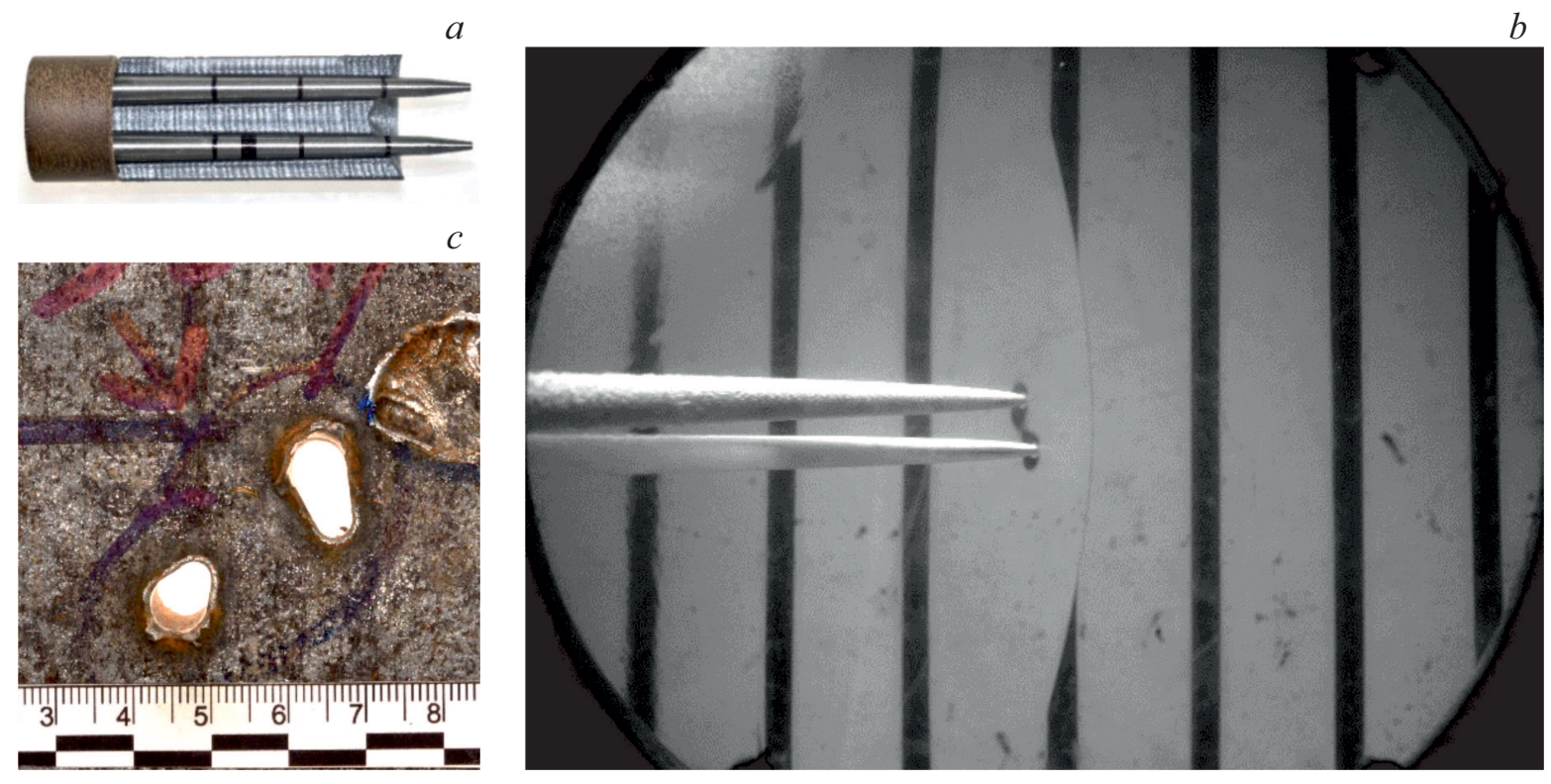

Рис. 3. Фотография двух ударников в сборке $(a)$, их совместное движение в воде со сверхзвуковой скоростью $1496 \mathrm{~m} / \mathrm{s}(b)$ и вид мишени после взаимодействия $(c)$. 
фотографирования (рис. 3,b) находятся на удалении $0.7 \mathrm{~m}$ от точки их входа в воду, их средняя скорость на наблюдаемом участке в пределах иллюминатора составила $1496 \mathrm{~m} / \mathrm{s}$, а абсолютное расстояние между их продольными осями находилось в диапазоне 16-18 mm. Через $1.6 \mathrm{~m}$ их скорость снизилась до $1417 \mathrm{~m} / \mathrm{s}$.

Наблюдаемое перед ударниками характерное искажение линий контрастной сетки (рис. $3, b$ ) свидетельствует о реализации сверхзвукового режима движения ударников с отошедшей ударной волной. Характерно, что во всей представленной серии экспериментов поверхность границ суперкаверн на начальном этапе входа в воду выглядит возмущенной и неоднородной. Контуры ударников внутри каверн в данной серии практически неразличимы в отличие от изображений каверн, полученных ранее при более низких скоростях [5,6,8], где поверхность каверны оптически прозрачна.

По форме оставленных в мишени отверстий (рис. 3, c) можно заключить, что максимальный угол между осью ударника и нормалью к поверхности в момент соударения составлял менее $5^{\circ}$. Расстояние между кавитаторами ударников в момент их попадания в стальную мишень ( $2.6 \mathrm{~m}$ от входа в воду) составило $18 \mathrm{~mm}$, при этом угол расхождения их траекторий не превысил $0.04^{\circ}$.

Таким образом, в результате проведенных исследований разработана конструкция ударника, способного сохранять целостность при входе в воду и движении в ней в режиме суперкавитации при скоростях, превышающих скорость звука в воде.

Впервые экспериментально продемонстрировано совместное устойчивое суперкавитирующее движение в воде двух ударников при скорости $1496 \mathrm{~m} / \mathrm{s}$ со скоростью входа в воду $1529 \mathrm{~m} / \mathrm{s}$, при этом угол расхождения их траекторий не превысил $0.04^{\circ}$ на дистанции $2.6 \mathrm{~m}$.

\section{Финансирование работы}

Исследование выполнено за счет гранта Российского научного фонда (проект № 19-19-00233).

\section{Конфликт интересов}

Авторы заявляют, что у них нет конфликта интересов.

\section{Список литературы}

[1] Kirschner I. Supercavitating projectile experiments at supersonic speeds // High-speed body motion in water. AGARD Report. 1997. V. 827. P. 35 (1-4). https:/www.sto.nato.int/publications/AGARD/AGARD-R-827/ AGARD-R-827.pdf

[2] Логвинович Г.В. // Тр. ЦАГИ. 1980. В. 2052. С. 3-11.

[3] Федоров С.В., Велданов В.А. // ЖТФ. 2013. Т. 83. В. 2. C. 15-20. https://journals.ioffe.ru/articles/10815

[4] Ибен У., Иванов Н.Г., Исаенко И.И., Шмидт А.А. // Письма в ЖТФ. 2015. Т. 41. В. 24. С. 1-8.

http://journals.ioffe.ru/articles/42589
[5] Ищенко А.Н., Афбанасьева С.А., Буркин В.В., Дьячковский А.С., Чупашев А.В. // Письма в ЖТФ. 2019. Т. 45. B. 20. C. 47-50. DOI: 10.21883/PJTF.2020.23.50343.18484 [Пер. версия: 10.1134/S1063785019100225].

[6] Буркин В.В., Акиншин Р.Н., Афанасьева С.А., Борисенков И.Л., Ищенко А.Н., Хабибуллин М.В., Чупашев А.В., Югов Н.Т. // Инж.-физ. журн. 2018. Т. 91. № 3. С. 701-708. [Пер. версия: 10.1007/s10891-018-1787-y].

[7] Урик Р.Джс. Основы гидроакустики. Пер. с англ. Л.: Судостроение, 1978. $448 \mathrm{c}$.

[8] Ishchenko A., Burkin V., Diachkovskii A., Korolkov L., Chupashev A., Zykova A. // AIP Conf. Proc. 2016. V. 1770. P. 030011 (1-8). DOI: 10.1063/1.4963953 